\title{
The $\alpha_{1 \mathrm{~A} / \mathrm{C}^{-}}$and $\alpha_{1 \mathrm{~B}-\text { adrenergic receptors are required }}$ for physiological cardiac hypertrophy in the double-knockout mouse
}

\author{
Timothy D. O’Connell, ${ }^{1}$ Shinji Ishizaka, ${ }^{2}$ Akihiro Nakamura, ${ }^{3}$ Philip M. Swigart, ${ }^{1}$ \\ M.C. Rodrigo, ${ }^{1}$ Gregory L. Simpson, ${ }^{1}$ Susanna Cotecchia, ${ }^{4}$ D. Gregg Rokosh, ${ }^{5}$ \\ William Grossman, ${ }^{2}$ Elyse Foster, ${ }^{2}$ and Paul C. Simpson ${ }^{1}$ \\ ${ }^{1}$ Cardiology Division, San Francisco Veterans Affairs Medical Center, and the Cardiovascular Research Institute and \\ Department of Medicine, University of California San Francisco (UCSF), San Francisco, California, USA \\ ${ }^{2}$ Cardiology Division, Department of Medicine, UCSF, San Francisco, California, USA \\ ${ }^{3}$ Iwate Prefectural Miyako Hospital, Iwate, Japan \\ ${ }^{4}$ Institut de Pharmacologie et Toxocologie, Universite de Lausanne, Switzerland \\ ${ }^{5}$ Cardiology Division, Department of Medicine, University of Louisville, Louisville, Kentucky, USA
}

\begin{abstract}
Catecholamines and $\alpha_{1}$-adrenergic receptors ( $\alpha_{1}$-ARs) cause cardiac hypertrophy in cultured myocytes and transgenic mice, but heart size is normal in single KOs of the main $\alpha_{1}-\mathrm{AR}$ subtypes, $\alpha_{1 \mathrm{~A} / \mathrm{C}}$ and $\alpha_{1 \mathrm{~B}}$. Here we tested whether $\alpha_{1}$-ARs are required for developmental cardiac hypertrophy by generating $\alpha_{1 \mathrm{~A} / \mathrm{C}}$ and $\alpha_{1 \mathrm{~B}}$ double $\mathrm{KO}(\mathrm{ABKO})$ mice, which had no cardiac $\alpha_{1}$-AR binding. In male ABKO mice, heart growth after weaning was $40 \%$ less than in WT, and the smaller heart was due to smaller myocytes. Body and other organ weights were unchanged, indicating a specific effect on the heart. Blood pressure in ABKO mice was the same as in WT, showing that the smaller heart was not due to decreased load. Contractile function was normal by echocardiography in awake mice, but the smaller heart and a slower heart rate reduced cardiac output. $\alpha_{1}$-AR stimulation did not activate extracellular signal-regulated kinase (Erk) and downstream kinases in ABKO myocytes, and basal Erk activity was lower in the intact $\mathrm{ABKO}$ heart. In female $\mathrm{ABKO}$ mice, heart size was normal, even after ovariectomy. Male ABKO mice had reduced exercise capacity and increased mortality with pressure overload. Thus, $\alpha_{1}$-ARs in male mice are required for the physiological hypertrophy of normal postnatal cardiac development and for an adaptive response to cardiac stress.
\end{abstract}

J. Clin. Invest. 111:1783-1791 (2003). doi: 10.1172/JCI200316100.

\section{Introduction}

Cardiac growth during development occurs in two phases, initially by myocyte hyperplasia, but primarily by myocyte hypertrophy after the early postnatal period. Postnatal cardiac hypertrophy is a normal physiological process that increases heart size to maintain cardiac output to the growing organism (1). Catecholamines such as norepinephrine are one signal for cardiac hypertrophy, and their role in pathological hypertrophy in disease is well characterized $(2,3)$, yet their role in physiological hypertrophy during development is less well studied. Knockout of the enzymes that syn-

Received for publication June 6, 2002, and accepted in revised form March 25, 2003.

Address correspondence to: Paul C. Simpson, Veterans Affairs Medical Center 111C8, 4150 Clement Street, San Francisco, California 94121, USA. Phone: (415) 221-4810 ext. 3200;

Fax: (415) 750-6950; E-mail: pcs@itsa.ucsf.edu.

Conflict of interest: The authors have declared that no conflict of interest exists.

Nonstandard abbreviations used: adrenergic receptor (AR); myosin heavy chain (MyHC); $\alpha_{1 \mathrm{~A} / \mathrm{C}^{-}}$and $\alpha_{1 \mathrm{~B}}$-AR double $\mathrm{KO}$ (ABKO); extracellular signal-regulated kinase (Erk); ribonuclease protection assay (RPA); heart rate (HR); transverse aortic constriction (TAC); heart weight (HW); body weight (BW); left ventricular (LV); phenylephrine (PE). thesize catecholamines leads to death in utero from cardiac defects, indicating that catecholamines are required for prenatal cardiac development (4). Cardiac adrenergic innervation increases from birth to weaning (1), and thus, increased norepinephrine release from adrenergic nerves might be involved in postnatal heart growth as well.

Norepinephrine stimulates all adrenergic receptors (ARs), $\alpha_{1}, \alpha_{2}$, and $\beta$, and alters hemodynamic loading. However, experiments in cultured neonatal rat cardiac myocytes show clearly that catecholamines induce hypertrophy via $\alpha_{1}$-ARs, independent of loading (2, 5, $6)$. Of the three $\alpha_{1}$-AR subtypes, $\alpha_{1 \mathrm{~A} / \mathrm{C}}, \alpha_{1 \mathrm{~B}}$, and $\alpha_{1 \mathrm{D}}$, culture studies suggest that the $\alpha_{1 \mathrm{~A} / \mathrm{C}}-\mathrm{AR}$ mediates myocyte hypertrophy (7).

Experiments in transgenic mice partly support the culture results and the idea that $\alpha_{1}$-ARs can be sufficient to induce hypertrophy during development. An activated mutant of the $\alpha_{1 \mathrm{~B}}$-AR subtype causes hypertrophy when overexpressed in cardiac myocytes with the $\alpha$-myosin heavy chain $(\alpha-\mathrm{MyHC})$ promoter (8). The WT $\alpha_{1 \mathrm{~B}}$ overexpressed by an $\alpha_{1 \mathrm{~B}}$ promoter also increases heart size (9).

On the other hand, heart size is not changed by $\alpha$-MyHC-directed overexpression of either the WT $\alpha_{1 \mathrm{~B}}$ or the WT $\alpha_{1 \mathrm{~A} / \mathrm{C}}(10,11)$. Furthermore, growth of the 


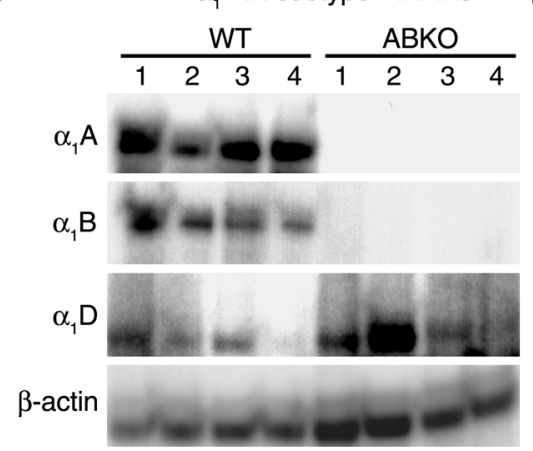

b

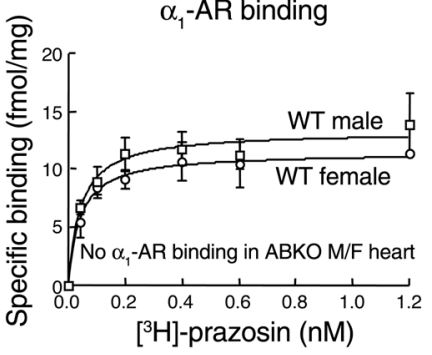

\section{Figure 1}

$\alpha_{1}$-AR subtype mRNA levels and receptor binding in hearts from $A B K O$ and WT mice. (a) $\alpha_{1}$-AR subtype mRNAs by RPA. RNA was from ventricles of 10week-old male mice. (b) $\alpha_{1}$-AR saturation binding. $\left[{ }^{3} \mathrm{H}\right]$-prazosin was used with ventricular membranes from 10-week-old male and female mice; $n=4$ of each sex and genotype.

and $10 \mu \mathrm{M}$ phentolamine (RBI, Natick, Massachusetts, USA) to define nonspecific binding (17). Total receptor number $\left(B_{\max }\right)$ and binding affinity $\left(K_{D}\right)$ were cal-

heart is normal in the individual $\alpha_{1 \mathrm{~B}}$ and $\alpha_{1 \mathrm{~A} / \mathrm{C} \text {-subtype }}$ $\mathrm{KO}$ mice $(12,13)$. Similarly, heart size is not reduced in a double $\beta$-AR KO (14) and is increased in a double $\alpha_{2}$-AR KO due to enhanced norepinephrine release (15). Therefore, although catecholamines and $\alpha_{1}$-ARs are implicated in cardiac hypertrophy, none of the individual ARs, particularly $\alpha_{1}$-ARs, appears to be essential for postnatal cardiac growth in vivo.

One explanation for normal cardiac development in the single $\alpha_{1}$-AR KO mice is functional redundancy of the different $\alpha_{1}$-AR subtypes. Therefore, to test further the hypothesis that $\alpha_{1}$-ARs are required for hypertrophy, we generated a double $\mathrm{KO}-\mathrm{ABKO}$ - of the two main $\alpha_{1}$-AR subtypes in the heart, the $\alpha_{1 \mathrm{~A} / \mathrm{C}}$ and $\alpha_{1 \mathrm{~B}}$. We studied cardiac structure and function during the hypertrophy of normal postnatal development. Hypertrophy during development is the most common type of cardiac hypertrophy and is an example of physiological hypertrophy, in which cardiac function remains normal or improves, in contrast with pathological hypertrophy, in which function deteriorates eventually. Our results show a load-independent and sex-specific requirement for $\alpha_{1}$-ARs in developmental hypertrophy and in the cardiac response to stress, and they implicate extracellular signal-regulated kinase (Erk) signaling in this effect.

\section{Methods}

Generation of $\alpha_{1 A / C}$ and $\alpha_{1 B}$ double $\mathrm{KO}$ mice. $\alpha_{1 \mathrm{~B}} \mathrm{KO}$ mice (C57BL/6, 129Sv) (12) were mated with $\alpha_{1 \mathrm{~A} / \mathrm{C}} \mathrm{KO}$ mice (FVB, 129Sv) (13) to produce $\mathrm{F}_{1}$ mice heterozygous for both KOs. $F_{1}$ heterozygous mice were mated to produce $\mathrm{F}_{2} \mathrm{WT}$ and $\mathrm{ABKO}$ mice, and breeding pairs from these two lines produced offspring used in most experiments. Concurrently, mice heterozygous for both KOs were backcrossed with C57BL/ 6 mice to produce fifthgeneration congenic mice.

Ribonuclease protection assay. Ribonuclease protection assay (RPA) used $25 \mu \mathrm{g}$ total ventricular RNA (Trizol, GIBCO BRL; Life Technologies Inc., Gaithersburg, Maryland, USA); bands were quantified using ImageQuant (Molecular Dynamics, Sunnyvale, California, USA) and normalized to $\beta$-actin (Ambion Inc., Austin, Texas, USA) $(7,16)$.

Radioligand binding assay. Saturation binding in heart $100,000 \mathrm{~g}$ membranes used 0.04-1.2 $\mathrm{nM}\left[{ }^{3} \mathrm{H}\right]$-prazosin culated by nonlinear regression using GraphPad Prism (GraphPad Software Inc., San Diego, California, USA). Echocardiography. Echocardiography was done with an Acuson Sequoia C256 (Acuson, Mountain View, California, USA) with a $15-\mathrm{MHz}$ linear array transducer. Mice were under anesthesia with isoflurane or were awake and gently restrained (18).

Blood pressure and heart rate. Systolic BP and heart rate (HR) were measured using a noninvasive computerized tail cuff system (BP-2000; Visitech Systems, Apex, North Carolina, USA) (13). Mice were trained for 3 days, and recordings were made on the next 5 days, with at least 15 of 20 successful readings each day.

Heart histology. Excised hearts were rinsed in PBS, fixed with $4 \%$ paraformaldehyde, embedded in paraffin, and sectioned at $10 \mu \mathrm{m}$. Alternately, hearts were fixed in situ after arrest in diastole with $40 \mathrm{mM} \mathrm{KCl}$, or embedded in Tissue-Tek O.C.T. compound (Miles Laboratories Inc., Elkhart, Indiana, USA) and frozen. Paraffin-embedded coronal sections were stained with fluorescein-conjugated wheat germ agglutinin and Hoechst 33342, and myocyte cross-sectional area was measured by fluorescence microscopy and NIH Image. Heart cross-sectional area was measured from $10-\mu \mathrm{m}$ frozen sagittal sections. Myocyte isolation and volume. Ventricular myocytes were isolated as described (19), except that collagenase perfusion was at $4 \mathrm{ml} / \mathrm{min}$. Isolated myocytes were fixed with $5 \%$ formaldehyde in PBS, and myocyte volume was measured using a Coulter Multisizer with Accucomp software (Coulter Instruments Inc., Hialeah, Florida, USA) (20). Myocyte surface area and nucleation. Isolated myocytes were plated in two-well slides, fixed with 30\% acetone $/ 70 \%$ ethanol, and viewed under phase contrast (Eclipse E600; Nikon Inc., Melville, New York, USA). Surface area was measured with NIH Image software from digital images (SPOT digital camera; Diagnostic Instruments Inc., Sterling Heights, Michigan, USA). Myocyte nuclei were counted in cells stained with Hoechst 33342 and visualized by fluorescence microscopy (Eclipse E600; Nikon Inc.).

Culture of adult mouse myocytes and Western blot. Isolated myocytes were plated at 50 rod-shaped cells per $\mathrm{mm}^{2}$ on laminin-coated $35-\mathrm{mm}$ dishes in $2 \% \mathrm{CO}_{2}$ at $37^{\circ} \mathrm{C}(19)$. After overnight culture in MEM with HBSS, $1 \mathrm{mg} / \mathrm{ml}$ $\mathrm{BSA}$, and $10 \mathrm{mM}$ butanedione monoxime, myocytes were treated with the agonists shown in Figure 5. Medi- 
um was aspirated after 15 minutes, and lysates were collected in $100 \mu \mathrm{l} 1 \times$ Laemmli sample buffer (Bio-Rad Laboratories Inc., Hercules, California, USA), separated on $10 \%$ polyacrylamide gels (Bio-Rad Laboratories Inc.), and transferred to nitrocellulose membranes (Bio-Rad Laboratories Inc.). Blots were blocked with 5\% nonfat dry milk and probed with antibodies to the following phosphorylated (activated) and total signaling proteins: p38, Akt, p70S6K, p90RSK, and p44/42 MAPK/Erk1/2 (all from Cell Signaling Technology Inc., Beverly, Massachusetts, USA), and $\mathrm{Ca}^{2+} /$ calmodulin kinase II (CaMKII) (Affinity BioReagents Inc., Golden, Colorado, USA). Bands were detected by Enhanced Chemiluminescence Reagent (Amersham Pharmacia Biotech, Piscataway, New Jersey, USA).

Erk1/2 activity in intact heart. Activated Erk1/2 dually phosphorylated on T202/Y204 was immunoprecipitated from ventricular lysates and used to phosphorylate an Elk1 fusion protein in vitro; phospho-Elk1 (S383) was detected by Western blot (Cell Signaling Technology Inc.).

Ovariectomy. Bilateral ovariectomy or sham operation was done at weaning ( 3 weeks). Mice were fed an isoflavone-free diet to prevent the ingestion of phytoestrogens and were sacrificed at 12 weeks.

Exercise testing. Exercise capacity was quantified by two approaches. For voluntary exercise, individual mice were placed in a cage containing a freely spinning running wheel attached to a chronometer. For forced exercise, individual mice were placed on a motorized treadmill with a mild motivational shock bar (Eco-6M Treadmill; Columbus Instruments, Columbus, Ohio, USA).

Transverse aortic constriction. Transverse aortic constriction (TAC) was done without intubation under anesthesia with isoflurane, and the pressure gradient across the stenosis was estimated by echocardiography in awake mice (18). The surgeon and the echocardiographer were both blinded to genotype.

Data analysis. Results are mean \pm SEM. Mean values were compared by unpaired two-tailed Student's $t$ test, and regression curves were compared by $F$ test. $P<0.05$ was considered significant.

\section{Results}

$\alpha_{1 A / C}$ and $\alpha_{1 B}$ double KO mice. To generate ABKO mice, $\alpha_{1 \mathrm{~B}} \mathrm{KO}$ mice were mated with $\alpha_{1 \mathrm{~A} / \mathrm{C}} \mathrm{KO}$ mice to produce mice heterozygous for both KOs. Initial matings of double-heterozygous mice produced 235 mice (116 males, 119 females, average litter size 8), and ABKO mice were born in expected mendelian frequency (15 expected, 17 observed, 8 males, 9 females). ABKO mice were viable and free from obvious disease to 1 year.

$\alpha_{1}$-ARs in the heart. To confirm the double $\mathrm{KO}$, we measured $\alpha_{1}$-AR subtype mRNA levels (A/C, B, and D) by RPA. In male ABKO hearts, only the $\alpha_{1 D}$-AR mRNA was expressed, whereas in WT hearts, all three subtypes were present (Figure 1a). In ABKO hearts, $\alpha_{1}$-AR binding was not detected in males or females by saturation analysis with $\left[{ }^{3} \mathrm{H}\right]$-prazosin (Figure $1 b$ ). Thus, the $\alpha_{1 \mathrm{D}}$ mRNA is not translated in the heart, or the $\alpha_{1 \mathrm{D}}$ protein is below the level of detection in the binding assay. These results confirmed the double $\mathrm{KO}$ and indicated that the $\alpha_{1 \mathrm{~A} / \mathrm{C}}$ and $\alpha_{1 \mathrm{~B}}$ subtypes accounted for all $\alpha_{1}$-AR binding in the WT heart.

Postnatal heart growth. To determine whether $\alpha_{1}$-ARs are required for normal postnatal growth of the heart, we measured heart weight (HW) in young adult (9- to 14-week-old) male ABKO mice (Figure 2 and Table 1). In male $\mathrm{ABKO}$ mice, atrial, ventricular, and total heart wet weights were reduced significantly $(18 \%, 16 \%$, and $16 \%, P<0.001)$, but body weight (BW) was unchanged (Table 1). Thus, HW/BW ratio was reduced significantly in the ABKO mice $(13 \%, P<0.001$; Table 1$)$. By echocardiography in anesthetized mice, left ventricu$\operatorname{lar}(\mathrm{LV})$ wall thickness and end-systolic chamber size were reduced significantly in the ABKO mice, and LV end-diastolic chamber size tended to be smaller (Table 2). Thus echocardiographic LV mass was decreased significantly (Table 2), in agreement with HW (Table 1). Liver, kidney, and lung weights were the same in male ABKO and WT mice, both absolute and normalized to BW (Table 1). Therefore, in male mice, disruption of both the $\alpha_{1 \mathrm{~A} / \mathrm{C}^{-}}$and the $\alpha_{1 \mathrm{~B}}$-ARs reduced heart growth specifically. HW, wall thickness, and chamber size were all reduced.

Time course of postnatal heart growth. To determine when during cardiac development growth of the heart was reduced in male $\mathrm{ABKO}$ mice, we measured $\mathrm{HW}$ starting
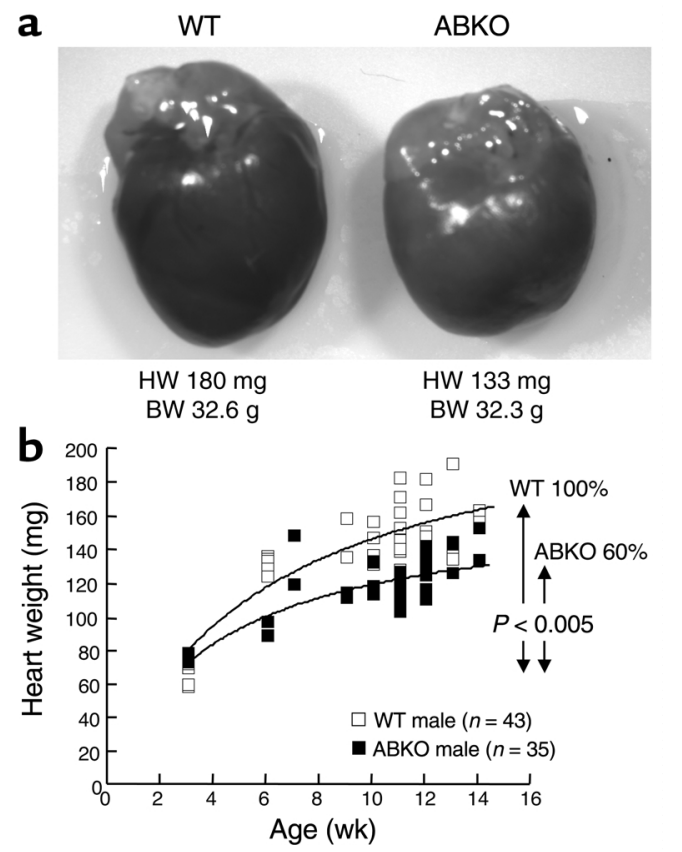

Figure 2

Heart growth in male ABKO and WT mice. (a) Typical hearts at 12 weeks. Twelve-week-old male mice had the wet HWs and BWs shown. (b) HW versus age. Wet $\mathrm{HW}$ in male mice from weaning (3 weeks) to young adulthood (14 weeks) is plotted versus age. Curves were fit using nonlinear regression $(F=17.81, P<0.005)$. Heart growth after weaning in the ABKO mice was only $60 \%$ of that in WT; BW was the same as in WT (not shown). 
Table 1

Heart and organ weights, myocyte size, and mRNA levels in ABKO mice

\begin{tabular}{|c|c|c|c|c|c|c|c|c|}
\hline \multirow{2}{*}{$\begin{array}{l}\text { Sex } \\
\text { Genotype }\end{array}$} & \multicolumn{3}{|c|}{ Male } & \multicolumn{3}{|c|}{ Female } & \multicolumn{2}{|c|}{ Male/Female } \\
\hline & WT & $\mathrm{ABKO}$ & $\begin{array}{c}\mathrm{ABKO} / \mathrm{WT} \\
(\%)\end{array}$ & WT & ABKO & $\begin{array}{c}\mathrm{ABKO} / \mathrm{WT} \\
(\%)\end{array}$ & $\begin{array}{l}\text { WT } \\
(\%)\end{array}$ & $\begin{array}{c}\text { ABKO } \\
(\%)\end{array}$ \\
\hline $\mathrm{BW}(\mathrm{g})$ & $31.2 \pm 0.5(33)$ & $29.8 \pm 0.7(27)$ & 96 & $26.0 \pm 0.9(16)$ & $25.4 \pm 0.5(15)$ & 98 & $120^{\mathrm{B}}$ & $118^{\mathrm{C}}$ \\
\hline \multicolumn{9}{|l|}{$\mathrm{HW}$} \\
\hline Atria $(\mathrm{mg})$ & $9.7 \pm 0.3(31)$ & $7.9 \pm 0.4(25)$ & $82^{\mathrm{A}}$ & $6.3 \pm 0.3(16)$ & $6.6 \pm 0.5(15)$ & 105 & $154^{\mathrm{B}}$ & $120^{C}$ \\
\hline Ventricles (mg) & $136 \pm 3(31)$ & $115 \pm 3(25)$ & $84^{\mathrm{A}}$ & $102 \pm 3(16)$ & $96 \pm 2(15)$ & $94^{\mathrm{A}}$ & $133^{\mathrm{B}}$ & $120^{C}$ \\
\hline Heart $(\mathrm{mg})$ & $147 \pm 3(33)$ & $122 \pm 3(27)$ & $84^{\mathrm{A}}$ & $109 \pm 3(16)$ & $103 \pm 2(15)$ & 94 & $135^{\mathrm{B}}$ & $118^{\mathrm{C}}$ \\
\hline $\mathrm{HW} / \mathrm{BW}\left(\times 10^{-3}\right)$ & $4.7 \pm 0.1(33)$ & $4.1 \pm 0.1(27)$ & $87^{A}$ & $4.2 \pm 0.1(16)$ & $4.1 \pm 0.1(15)$ & 98 & $112^{\mathrm{B}}$ & 100 \\
\hline \multicolumn{9}{|l|}{ Myocyte size and mRNA } \\
\hline Myocyte volume $\left(\mu \mathrm{m}^{3}\right)$ & $19,647 \pm 722(6)$ & $14,688 \pm 1,111(7)$ & $75^{\mathrm{A}}$ & $11,513 \pm 529(4)$ & $11,371 \pm 264(3)$ & 99 & $170^{\mathrm{B}}$ & 128 \\
\hline Myocyte surface area $\left(\mu \mathrm{m}^{2}\right)$ & $3,266 \pm 40(3)$ & $2,505 \pm 180(3)$ & $77^{\mathrm{A}}$ & ND & ND & & & \\
\hline Myocyte csa $\left(\mu \mathrm{m}^{2}\right)$ & $210 \pm 24(2)$ & $141 \pm 10(2)$ & $67^{\mathrm{A}}$ & ND & ND & & & \\
\hline MyHC $(\alpha+\beta)$ (MyHC/actin) & $1.80 \pm 0.05(6)$ & $1.57 \pm 0.07(6)$ & $87^{A}$ & ND & ND & & & \\
\hline ANF (ANF/actin) & $0.35 \pm 0.02(6)$ & $0.21 \pm 0.02(6)$ & $60^{\mathrm{A}}$ & ND & ND & & & \\
\hline \multicolumn{9}{|l|}{ Liver } \\
\hline Liver weight $(\mathrm{g})$ & $1.4 \pm 0.1(18)$ & $1.4 \pm 0.1(14)$ & 100 & $1.2 \pm 0.1(11)$ & $1.1 \pm 0.1(8)$ & 92 & $117^{\mathrm{B}}$ & $127^{c}$ \\
\hline Liver weight/BW $\left(\times 10^{-2}\right)$ & $4.6 \pm 0.1(18)$ & $4.6 \pm 0.1(14)$ & 100 & $4.8 \pm 0.1(11)$ & $4.4 \pm 0.2(8)$ & 92 & 96 & 109 \\
\hline \multicolumn{9}{|l|}{ Lung } \\
\hline Lung weight (mg) & $177 \pm 4(18)$ & $164 \pm 5(14)$ & 93 & $165 \pm 6(11)$ & $157 \pm 7(8)$ & 95 & 107 & 104 \\
\hline Lung weight/BW $\left(\times 10^{-3}\right)$ & $5.8 \pm 0.2(18)$ & $5.6 \pm 0.2(14)$ & 97 & $6.7 \pm 0.4(11)$ & $6.2 \pm 0.3(8)$ & 93 & 87 & 90 \\
\hline \multicolumn{9}{|l|}{ Kidney } \\
\hline Right kidney (mg) & $213 \pm 7(18)$ & $210 \pm 10(14)$ & 99 & $135 \pm 6(11)$ & $158 \pm 5(8)$ & $117^{\mathrm{A}}$ & $158^{\mathrm{B}}$ & $133^{C}$ \\
\hline Kidney weight/BW $\left(\times 10^{-3}\right)$ & $6.9 \pm 0.2(18)$ & $7.1 \pm 0.3(14)$ & 103 & $5.5 \pm 0.3(11)$ & $6.2 \pm 0.2(8)$ & $113^{\mathrm{A}}$ & $125^{\mathrm{B}}$ & $114^{C}$ \\
\hline
\end{tabular}

Heart and organ weights, myocyte size, and mRNA levels were measured in young adult (9- to 14-week-old) ABKO and WT mice of both sexes. Chamber weights are combined right and left. Values are mean \pm SEM with the numbers of mice in parentheses. HW, heart weight; BW, body weight; csa, cross-sectional area; ANF, atrial natriuretic factor; ND, not determined. $P<0.05$; ${ }^{A} A B K O$ vs. WT; ${ }^{B}$ male vs. female $W T$; ${ }^{C}$ male vs. female ABKO.

at weaning ( 3 weeks) and continuing through young adulthood (14 weeks; Figure 2b). Litter sizes were matched to eliminate any impact on development. In WT mice, HW approximately doubled from weaning to young adulthood (Figure $2 \mathrm{~b}$ ). In ABKO mice, HW and $\mathrm{HW} / \mathrm{BW}$ ratio were the same as in $\mathrm{WT}$ at weaning. At 3 weeks, HW was $64.1 \pm 3.5 \mathrm{mg}$ in WT and $72.6 \pm 1.4 \mathrm{mg}$ in $\mathrm{ABKO}$ mice, and $\mathrm{HW} / \mathrm{BW}$ was $5.1 \pm 0.1$ in WT and $5.2 \pm 0.2$ in $\mathrm{ABKO}$ mice $(n=5 \mathrm{WT}, 4 \mathrm{ABKO}, P=\mathrm{NS})$. However, growth of the ABKO hearts was significantly less from weaning onward, with HW reaching only $84 \%$ of WT in the young adult $(P<0.05$; Table 1 and Figure
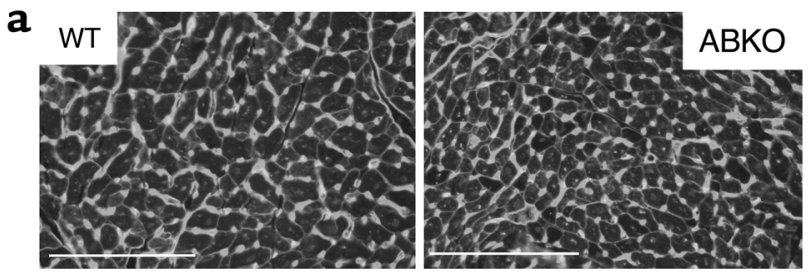

b WT
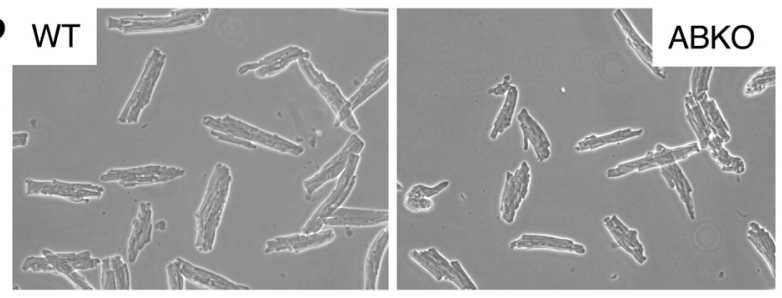
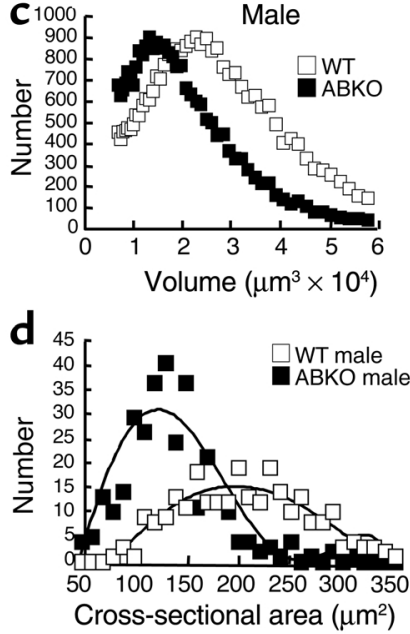
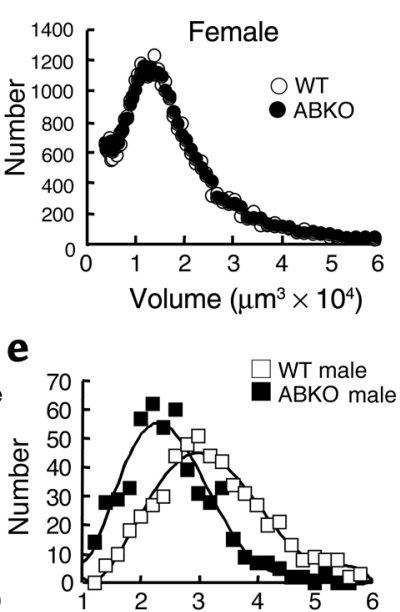

Surface area $\left(\mu \mathrm{m}^{2} \times 10^{3}\right)$

Figure 3

Myocyte size in ABKO and WT mice. (a) Ventricular cross sections. LV coronal sections from 10- to 11-week-old male mice were stained with fluorescein-conjugated wheat germ agglutinin for sarcolemmal membranes and with Hoechst 33342 for nuclei. Nuclei between myocytes are in nonmyocytes. $\times 40$. Scale bar, $100 \mu \mathrm{m}$. (b) Isolated myocytes. Myocytes were from hearts of 9- to 10 -week-old male mice. $\times 20$, phase contrast. (c) Myocyte volume. Myocyte volume by Coulter Multisizer is plotted versus myocyte number for representative hearts of each genotype and sex. (d) Myocyte cross-sectional area. Cross-sectional area in myocytes with a central nucleus, as in a, is plotted versus myocyte number (110-190 cells in each of two male hearts for each genotype). (e) Myocyte surface area. Surface areas of isolated myocytes as in b are plotted versus myocyte number (160-190 cells in each of three male hearts for each genotype). Group data are in Table 1. 
$2 \mathrm{~b})$. Growth curves modeled by nonlinear regression showed that the increase in heart size after weaning in the ABKO mice was only $60 \%$ of that in the WT $(P<0.005$; Figure $2 \mathrm{~b}$ ). BW of WT and ABKO mice did not differ significantly at any time. Thus, the $\alpha_{1 \mathrm{~A} / \mathrm{C}}$ and $\alpha_{1 \mathrm{~B}}$ subtypes were required for normal cardiac growth after weaning. Myocyte size. The mechanism of the smaller heart in the ABKO mice could have been either smaller myocytes or fewer myocytes. Reduced myocyte hypertrophy was more likely, because myocyte proliferation is largely complete by weaning (21). To test for a reduction in myocyte size in the intact heart, we measured myocyte cross-sectional area (Figure 3a). Heart and body weights of the ABKO and WT mice were matched to approximate the averages in Table 1 . Myocyte crosssectional area was reduced by $33 \%$ in the male ABKO heart $(P<0.05$; Figure $3 \mathrm{~d}$ and Table 1$)$.

To confirm the results from ventricular sections, we measured volume and surface area of myocytes isolated from hearts of $A B K O$ and WT mice matched for age and BW (Figure 3b). Myocyte volumes were quantified using a Coulter Multisizer, and surface area was measured by phase microscopy. In male ABKO mice, median myocyte volume was reduced by $25 \%$ and median myocyte surface area was reduced by $23 \%$ (Figure 3, c and e, and Table 1). Therefore, reduced myocyte hypertrophy could explain reduced cardiac hypertrophy after weaning in male $\mathrm{ABKO}$ mice.
Myocyte binucleation. During the first 2 weeks of normal postnatal development, mouse myocytes undergo a final round of DNA synthesis and become binucleate by nuclear division without cell division (21). A delay in terminal differentiation can increase the number of smaller, mononuclear myocytes (22) and was a potential explanation for the reduced myocyte hypertrophy observed in the male ABKO mice. However, the majority of isolated adult male myocytes were binucleate in both genotypes (ABKO, 91\% $\pm 0.2 \%$; WT, $89 \% \pm 0.7 \%$; $n=2$ hearts per genotype, $100-120$ myocytes per heart), suggesting normal terminal differentiation.

Myocyte mRNA levels. To test whether $\alpha_{1}$-ARs were required for normal transcription of cardiac genes during postweaning hypertrophy, we measured $\mathrm{MyHC}$ and atrial natriuretic factor (ANF) mRNA levels by RPA. In adult male $\mathrm{ABKO}$ ventricles, total $\mathrm{MyHC}$ and $\alpha$-MyHC mRNA was reduced by $13 \%(P<0.05$; Table 1 ), and $\beta-\mathrm{MyHC}$ mRNA ( $6 \%$ of total MyHC) tended to be lower (not shown). ANF mRNA was reduced by $40 \%$ $\left(P<0.05\right.$; Table 1). Thus, $\mathrm{KO}$ of both $\alpha_{1}$-ARs reduced myocyte mRNA levels.

Heart and myocyte size in congenic ABKO mice. To confirm that the small-heart phenotype observed in the $\mathrm{ABKO}$ mouse was not dependent on mixed strains, we measured heart and myocyte size in congenic $\mathrm{C} 57 \mathrm{BL} / 6$ mice. In congenic male ABKO mice, the small-heart phenotype was preserved (Figure 4). Heart cross-sec-

Table 2

Echocardiography in anesthetized ABKO mice

\begin{tabular}{|c|c|c|c|c|c|c|c|c|}
\hline \multirow{2}{*}{$\begin{array}{l}\text { Sex } \\
\text { Genotype }\end{array}$} & \multicolumn{3}{|c|}{ Male } & \multicolumn{3}{|c|}{ Female } & \multicolumn{2}{|c|}{ Male/Female } \\
\hline & WT & ABKO $A$ & $\begin{array}{c}\mathrm{ABKO} / \mathrm{WT} \\
(\%)\end{array}$ & WT & ABKO & $\begin{array}{c}\mathrm{ABKO} / \mathrm{WT} \\
(\%)\end{array}$ & $\begin{array}{l}\text { WT } \\
(\%)\end{array}$ & $\begin{array}{c}\mathrm{ABKO} \\
(\%)\end{array}$ \\
\hline$n$ & 16 & 11 & & 8 & 8 & & & \\
\hline $\mathrm{BW}(\mathrm{g})$ & $33.4 \pm 1.3$ & $31.0 \pm 1.3$ & 93 & $25.9 \pm 0.9$ & $26.6 \pm 1.4$ & 103 & $129^{B}$ & $117^{c}$ \\
\hline HR (beats/min) & $432 \pm 11$ & $435 \pm 22$ & 101 & $441 \pm 19$ & $438 \pm 25$ & 99 & 98 & 99 \\
\hline \multicolumn{9}{|l|}{ M-mode } \\
\hline LV posterior wall thickness, $\mathrm{D}(\mathrm{mm})$ & $0.61 \pm 0.02$ & $0.50 \pm 0.01$ & $82^{\mathrm{A}}$ & $0.49 \pm 0.02$ & $0.47 \pm 0.02$ & 96 & $124^{\mathrm{B}}$ & 106 \\
\hline $\mathrm{LV}$ anterior wall thickness, $\mathrm{D}(\mathrm{mm})$ & $0.74 \pm 0.03$ & $0.58 \pm 0.01$ & $78^{\mathrm{A}}$ & $0.59 \pm 0.02$ & $0.56 \pm 0.02$ & 95 & $125^{\mathrm{B}}$ & 104 \\
\hline $\mathrm{LV}$ internal dimension, $\mathrm{D}(\mathrm{mm})$ & $4.46 \pm 0.07$ & $4.28 \pm 0.07$ & 796 & $4.04 \pm 0.08$ & $4.13 \pm 0.12$ & $2 \quad 102$ & $110^{\mathrm{B}}$ & 104 \\
\hline $\mathrm{LV}$ posterior wall thickness, $\mathrm{S}(\mathrm{mm})$ & $0.77 \pm 0.02$ & $0.63 \pm 0.02$ & $282^{\mathrm{A}}$ & $0.62 \pm 0.02$ & $0.58 \pm 0.02$ & 94 & $124^{B}$ & 109 \\
\hline LV anterior wall thickness, $\mathrm{S}(\mathrm{mm})$ & $0.84 \pm 0.03$ & $0.68 \pm 0.02$ & $281^{\mathrm{A}}$ & $0.66 \pm 0.02$ & $0.64 \pm 0.01$ & 97 & $127^{\mathrm{B}}$ & 106 \\
\hline $\mathrm{LV}$ internal dimension, $\mathrm{S}(\mathrm{mm})$ & $3.19 \pm 0.07$ & $2.97 \pm 0.10$ & $93^{\mathrm{A}}$ & $2.870 \pm 0.13$ & $2.83 \pm 0.07$ & 99 & $113^{\mathrm{B}}$ & 105 \\
\hline Fractional shortening (\%) & $28 \pm 2$ & $31 \pm 1$ & $111^{\mathrm{A}}$ & $29 \pm 2.1$ & $31 \pm 1$ & 107 & 96 & 100 \\
\hline End-diastolic volume $(\mu \mathrm{l})$ & $92 \pm 4$ & $83 \pm 4$ & 90 & $69 \pm 4$ & $75 \pm 7$ & 109 & 133 & 111 \\
\hline End-systolic volume $(\mu \mathrm{l})$ & $34 \pm 2$ & $28 \pm 3$ & $82^{\mathrm{A}}$ & $26 \pm 4$ & $24 \pm 2$ & 92 & 131 & 117 \\
\hline Stroke volume $(\mu \mathrm{l})$ & $58 \pm 4$ & $55 \pm 3$ & 95 & $43 \pm 2$ & $51 \pm 6$ & 119 & $135^{\mathrm{B}}$ & 108 \\
\hline Ejection fraction (\%) & $62 \pm 3$ & $67 \pm 2$ & $108^{\mathrm{A}}$ & $64 \pm 3$ & $68 \pm 2$ & 106 & 96 & 99 \\
\hline Cardiac output ( $\mathrm{ml} / \mathrm{min})$ & $25 \pm 2$ & $24 \pm 2$ & 96 & $19 \pm 2$ & $22 \pm 3$ & 116 & $131^{\mathrm{B}}$ & 109 \\
\hline \multicolumn{9}{|l|}{$2 \mathrm{D}$} \\
\hline LV mass $(\mathrm{mg})$ & $113 \pm 6$ & $79 \pm 4$ & $70^{\mathrm{A}}$ & $71 \pm 4$ & $70 \pm 4$ & 99 & $159^{\mathrm{B}}$ & 113 \\
\hline $\mathrm{LV}$ mass index $\left(\mathrm{mg} / \mathrm{g} \times 10^{-3}\right)$ & $3.4 \pm 0.1$ & $2.6 \pm 0.2$ & $76^{\mathrm{A}}$ & $2.8 \pm 0.2$ & $2.7 \pm 0.1$ & 96 & $121^{\mathrm{B}}$ & 96 \\
\hline \multicolumn{9}{|l|}{ Pulsed-wave Doppler } \\
\hline Aortic flow rate $(\mathrm{m} / \mathrm{s})$ & $1.05 \pm 0.03$ & $1.05 \pm 0.04$ & $4 \quad 100$ & $0.90 \pm 0.05$ & $0.96 \pm 0.05$ & 107 & 117 & 109 \\
\hline LV wall stress $\left(\mathrm{g} / \mathrm{cm}^{2}\right)(n=8)$ & $140 \pm 8$ & $146 \pm 8$ & 104 & ND & ND & & & \\
\hline
\end{tabular}

Echocardiography was performed on anesthetized young adult (9- to 14-week-old) ABKO and WT mice of both sexes. 2D long axis and 2D-guided M-mode measurements were recorded. Calculations were made for LV mass by the truncated-ellipsoid method from $2 \mathrm{D}$ recordings, and from $\mathrm{M}$-mode measurements. Calculations were made for ventricular volumes by the cubed method [volume $=1.047 \times(\mathrm{LV} \text { internal dimension })^{3}$ ]. Stroke volume $(\mathrm{SV})=\mathrm{end}$-diastolic volume (EDV) - end-systolic volume $(E S V)$. Cardiac output $=\mathrm{HR} \times \mathrm{SV}$. Fractional shortening $=[($ LVIDD - LVIDS $) /$ LVIDD $] \times 100$, where LVID is LV internal dimension, $\mathrm{D}$ is diastole, and $\mathrm{S}$ is systole. Ejection fraction $=[(\mathrm{EDV}-\mathrm{ESV}) / \mathrm{EDV}] \times 100$. Wall stress $=[(1.35)($ SysBP $)($ LVIDS $)] /\{(4)(\mathrm{LVPWS})[1+(\mathrm{LVPWS}) /($ LVIDS $)]\}$ where SysBP is systolic BP from tail cuff measurements as in Table 3, and LVPWS is LV posterior wall thickness in systole. Values are mean \pm SEM. $P<0.05 ;{ }^{A} A B K O$ vs. WT; ${ }^{B}$ male vs. female WT; ${ }^{C}$ male vs. female ABKO. 

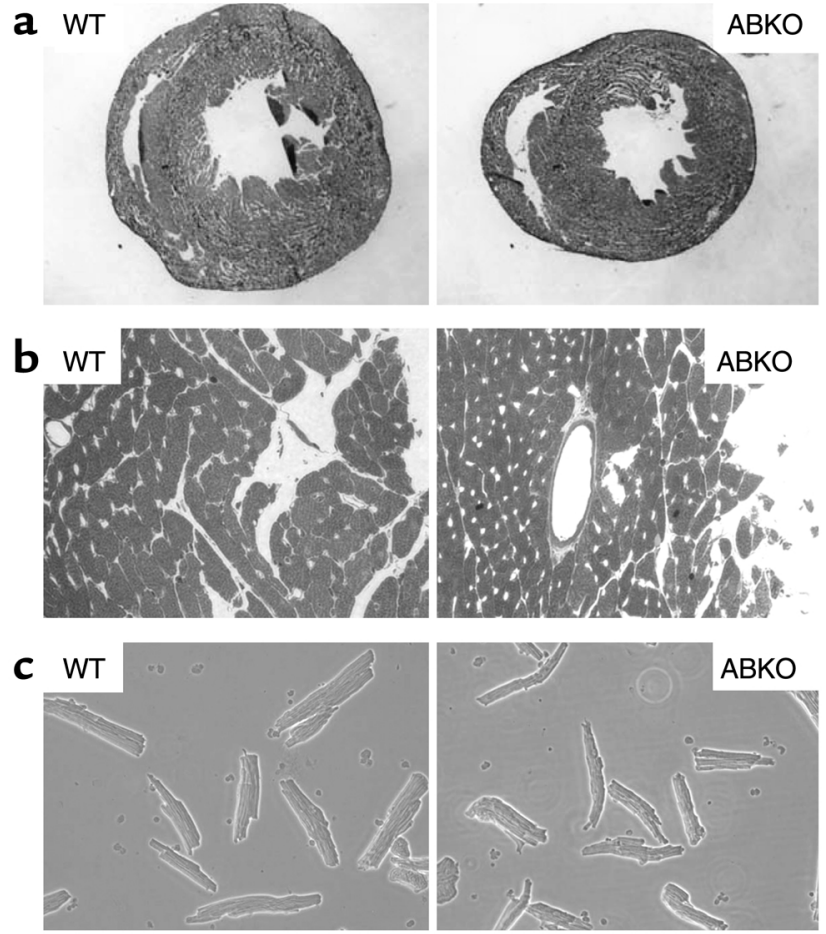

\section{Figure 4}

Heart and myocyte size in congenic 10- to 12-week-old male ABKO and WT mice. (a) Whole-heart cross sections. Frozen sections of whole heart were stained with hematoxylin. $\times 2.5$. The area of the ABKO section is $70 \%$ of that of the WT. (b) Ventricular cross sections. Hearts were fixed in diastole, and coronal sections of the left ventricle were stained with $1 \%$ toluidine blue. Small clear areas are capillaries that mark myocyte borders. $\times 40$. (c) Isolated myocytes. $\times 20$, phase contrast. Myocyte surface area was 3,259 $\pm 1,024 \mu \mathrm{m}^{2}$ in WT mice $(n=45)$ and $2,454 \pm 812 \mu \mathrm{m}^{2}$ in ABKO mice $(n=41,75 \%$ of WT, $P<0.05)$.

tional area was reduced 30\% (Figure 4a), and myocyte cross-sectional area and surface area were $25 \%$ smaller than those of the WT (Figure 4, b and c).

Systolic BP and HR. $\alpha_{1}$-ARs are potent vasoconstrictors (13), and their absence might decrease BP, thereby reducing cardiac growth. Indeed, the $\alpha_{1 \mathrm{~A} / \mathrm{C}} \mathrm{KO}$ mouse is hypotensive (13). Therefore, we measured resting systolic $\mathrm{BP}$ and $\mathrm{HR}$ in conscious young adult (8- to 10-week-old) mice by tail cuff (Table 3). BP was identical to that of WT in male ABKO mice, but HR was reduced significantly (Table 3 ). Therefore, the smaller heart in male ABKO mice did not result from decreased afterload.

Cardiac function by echocardiography. We used echocardiography to test whether the smaller ABKO heart functioned normally. In anesthetized mice, HR was $20-30 \%$ slower than in awake mice and was the same in ABKO and WT mice (Tables 2 and 3). In anesthetized male ABKO mice, indices of contractility (fractional shortening and ejection fraction) were increased slightly, and stroke volume, cardiac output, and aortic flow rate were the same as in WT (Table 2). LV wall stress, a recognized hypertrophic stimulus, was the same in ABKO and WT mice (Table 2).
Echocardiography in conscious mice avoided the reduction in HR caused by anesthesia and confirmed a significantly slower $\mathrm{HR}$ in male $\mathrm{ABKO}$ versus male WT mice (Table 3). In conscious male ABKO mice, end-diastolic volume was reduced significantly by $20 \%$ versus WT $(P<0.05)$. The smaller end-diastolic volume in the male ABKO heart caused a smaller stroke volume, even though ejection fraction and fractional shortening were normal (Table 3). Consequently, cardiac output was reduced significantly in male $\mathrm{ABKO}$ mice $(27 \%, P<0.05$; Table 3), due to the combination of a slower HR and a smaller stroke volume.

Hypertrophic signaling. To test mechanisms for reduced heart and myocyte hypertrophy in the $\mathrm{ABKO}$ mice, we stimulated cultured myocytes with the $\alpha_{1}$-AR agonist phenylephrine (PE) and other hypertrophic agonists and measured activation of Erk and PI3K/Akt, two pathways implicated in physiological hypertrophic signaling (23-26). PE activated Erk $1 / 2$ about twofold in WT male myocytes, and this response was lost in ABKO male myocytes (Figure 5a). PE in WT male myocytes also activated two kinases downstream from Erk1/2, p90RSK and p70S6K (23), and both PE responses were lost in the ABKO mice (Figure 5, b and c). PE responses were lost selectively, as a phorbol ester (PMA) and endothelin still activated Erk1/2 and downstream kinases in $\mathrm{ABKO}$ myocytes (Figure 5, b and c).

To estimate Erk activity in the intact heart under basal conditions, we immunoprecipitated activated Erk $1 / 2$ from ventricular lysates and measured phosphorylation in vitro of the Erk substrate Elk1. Erk1/2 activity in ABKO ventricles was only $29 \%$ of that in WT (77 \pm 16 vs. $263 \pm 26$ phospho-Elk 1 density units/ $\mu \mathrm{g}$ protein, $n=2-3$ hearts, $P<0.01$ ).

$\mathrm{PE}$ did not activate Akt in cultured WT or ABKO myocytes, but insulin activated Akt in both genotypes (Figure 5d). PE also did not activate p38 or CaMKII in WT or ABKO myocytes (data not shown). Failure to activate CaMKII was expected, because $\alpha_{1}$-ARs reduce calcium transients in mouse myocardium (27).

In summary, these results suggested that reduced activity of an Erk pathway was at least partly responsible for the small ABKO heart, but that the Akt pathway was intact.

Female mice. In contrast with males, female $\mathrm{ABKO}$ mice had hearts and myocytes the same size as those of the WT (Tables 1 and 2, and Figure 3c). Indeed, it was interesting to note that $\mathrm{KO}$ of both $\alpha_{1}$-ARs reduced male heart and myocyte size to that of females (Tables 1-3, last two columns). Only two differences from WT were detected in the female ABKO mice: bradycardia and larger kidneys (Tables $1-3$ ). Thus, $\alpha_{1}$-ARs were not required for normal postnatal growth of the female heart.

The female heart did express functional $\alpha_{1}$-ARs. In WT hearts, $\alpha_{1}$-AR levels and binding affinity were the same in both sexes ( $B_{\max }$ : male, $13 \pm 1 \mathrm{fmol} / \mathrm{mg}$ protein, female, $12 \pm 1 \mathrm{fmol} / \mathrm{mg}$ protein; $\mathrm{K}_{\mathrm{D}}$ : male, $43 \pm 2$ $\mathrm{pM}$, female, $50 \pm 5 \mathrm{pM} ; n=4, P=\mathrm{NS})$. Erk and Akt signaling in female myocytes were also similar to that in males (Figure 5, a and d). 

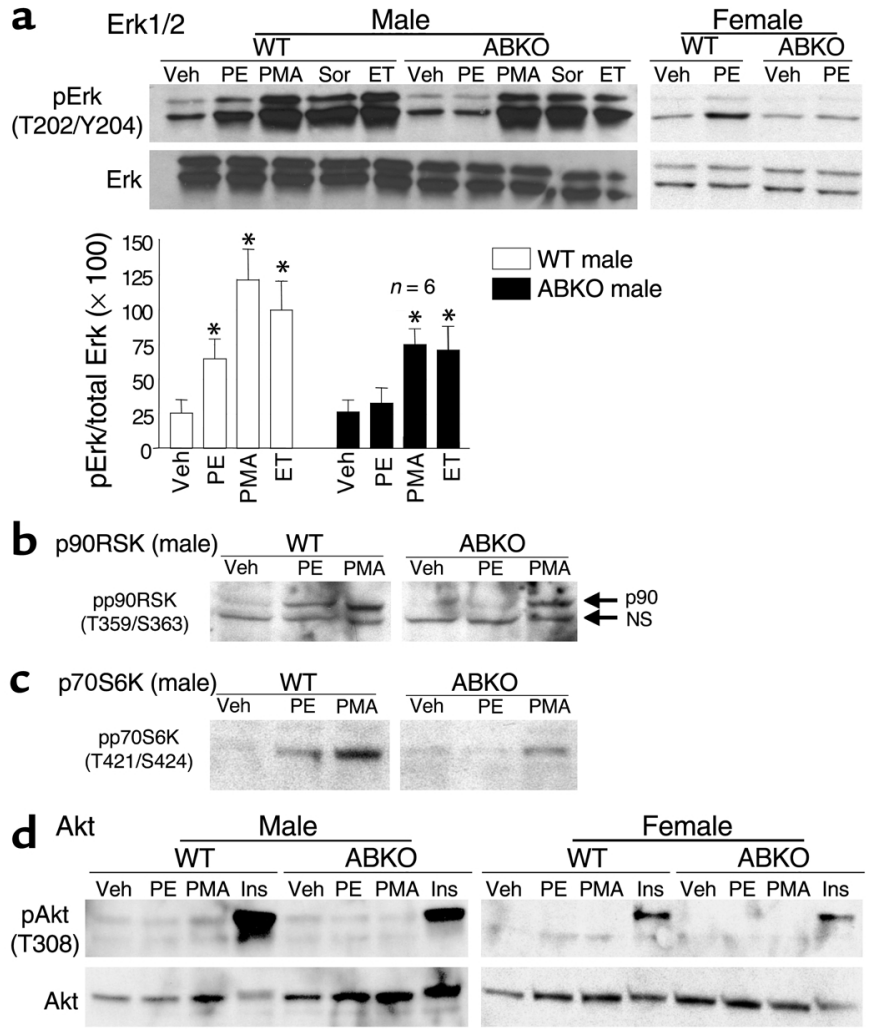

To test whether female sex hormones protected from $\mathrm{KO}$ of $\alpha_{1}$-ARs, we did ovariectomy at weaning (3 weeks) and studied the mice at age 12 weeks. Male heart growth was reduced in the ABKO mice over this same 3- to 12week interval (Figure $2 \mathrm{~b}$ ). Ovariectomy reduced uterine weight to $6-7 \%$ of that of sham-operated mice in both WT and ABKO mice $(n=3-6$ in each group, $P<0.025)$. However, ovariectomy had no effect in either genotype on BW, tibia length, HW, BP, or HR (data not shown). These same variables did not differ significantly between

\section{Figure 5}

Hypertrophic signaling in myocytes. Cultured myocytes from hearts of 10- to 11-week-old congenic WT and ABKO mice were treated for 15 minutes with PE $(20 \mu \mathrm{M}$, plus $2 \mu \mathrm{M}$ timolol); phorbol 12-myristate, 13-acetate (PMA, $100 \mathrm{nM}$ ); sorbitol (Sor, $1 \mathrm{M}$ ); endothelin (ET, $10 \mathrm{nM})$; insulin (Ins, $6 \mu \mathrm{M})$; or vehicle. Western blots were done for (a) phospho-Erk1/2 (pErk) and total Erk1/2, (b) phospho-p90RSK (pp90RSK), (c) phospho-p70S6K (pp70S6K), and (d) phospho-Akt (pAkt) and total Akt. In a, the bar graphs summarize Erk1/2 data from six hearts in each group. In $\mathbf{b}$, a nonspecific (NS) band is indicated with anti-pp90RSK. In d, a second pAkt antibody (S473) gave identical results (not shown). Total p90RSK (b) and total p70S6K (c) were the same in WT and ABKO mice (not shown). ${ }^{*} P<0.05$ vs. Veh.

WT and ABKO mice after ovariectomy, except that HR was $15 \%$ lower in the ABKO mice (data not shown), as observed in nonoperated female mice (Table 3). Thus, female sex hormones did not explain why the female heart was unaffected by the ABKO.

Response of the ABKO to stress. We used exercise and aortic banding to test whether the small male ABKO heart had an adaptive response to cardiac stress. Voluntary exercise was tested with a running wheel. WT mice ran a nightly average of about $6 \mathrm{~km}$ over about 4 hours at $22 \mathrm{~m} / \mathrm{min}$, and ABKO mice ran significantly less by all measures (Figure 6a). To test whether this result simply reflected motivational factors, we used forced exercise on a motorized treadmill. ABKO mice ran significantly less on the treadmill, measured either at a single session, or over 20 consecutive daily training sessions (Figure $6 \mathrm{~b}$, left and right). Thus, exercise capacity by two independent assays was reduced significantly in ABKO mice.

We used TAC to test the response to pressure overload. The gradient across the stenosis at 14 days was similar in WT and ABKO mice $(99 \pm 6 \mathrm{mmHg}, n=14$, in WT vs. $105 \pm 8 \mathrm{mmHg}, n=8$, in ABKO, $P=\mathrm{NS}$ ). However, survival to 14 days after TAC was only $56 \%$ in the ABKO ver-

Table 3

Cardiac function in conscious ABKO mice

\begin{tabular}{|c|c|c|c|c|c|c|c|c|}
\hline \multirow{2}{*}{$\begin{array}{l}\text { Sex } \\
\text { Genotype }\end{array}$} & \multicolumn{3}{|c|}{ Male } & \multicolumn{3}{|c|}{ Female } & \multicolumn{2}{|c|}{ Male/Female } \\
\hline & WT & ABKO & $\mathrm{ABKO} / \mathrm{WT}(\%)$ & WT & ABKO & ABKO/WT (\%) & WT (\%) & $\mathrm{ABKO}(\%)$ \\
\hline \multicolumn{9}{|l|}{ Tail cuff } \\
\hline$n$ & 14 & 11 & & 11 & 11 & & & \\
\hline Systolic BP (mmHg) & $111 \pm 2$ & $112 \pm 3$ & 101 & $111 \pm 3$ & $111 \pm 4$ & 100 & 100 & 101 \\
\hline $\mathrm{HR}$ (beats/min) & $622 \pm 10$ & $568 \pm 15$ & $91^{\mathrm{A}}$ & $604 \pm 15$ & $578 \pm 13$ & 96 & 103 & 98 \\
\hline \multicolumn{9}{|l|}{ Echocardiography } \\
\hline$n$ & 4 & 5 & & 5 & 4 & & & \\
\hline $\mathrm{BW}(\mathrm{g})$ & $36 \pm 2$ & $33 \pm 2$ & 92 & $25 \pm 1$ & $23 \pm 1$ & 92 & $144^{\mathrm{B}}$ & $143^{C}$ \\
\hline HR (beats/min) & $561 \pm 10$ & $496 \pm 6$ & $88^{\mathrm{A}}$ & $575 \pm 13$ & $531 \pm 13$ & $92^{\mathrm{A}}$ & 98 & 93 \\
\hline \multicolumn{9}{|l|}{ M-mode } \\
\hline Fractional shortening (\%) & $54 \pm 2$ & $58 \pm 3$ & 107 & $56 \pm 1$ & $54 \pm 3$ & 96 & 96 & 107 \\
\hline End-diastolic volume $(\mu \mid)$ & $60 \pm 3$ & $48 \pm 3$ & $80^{\mathrm{A}}$ & $41 \pm 2$ & $49 \pm 7$ & 120 & $146^{\mathrm{B}}$ & 98 \\
\hline End-systolic volume $(\mu \mathrm{l})$ & $6 \pm 1$ & $4 \pm 1$ & 67 & $4 \pm 0$ & $6 \pm 1$ & 150 & 150 & 67 \\
\hline Stroke volume $(\mu \mathrm{l})$ & $54 \pm 2$ & $44 \pm 3$ & $81^{\mathrm{A}}$ & $38 \pm 2$ & $44 \pm 6$ & 116 & $142^{\mathrm{B}}$ & 100 \\
\hline Ejection fraction (\%) & $90 \pm 1$ & $92 \pm 2$ & 102 & $92 \pm 1$ & $90 \pm 2$ & 98 & 98 & 102 \\
\hline Cardiac output (ml/min) & $30 \pm 1$ & $22 \pm 3$ & $73^{\mathrm{A}}$ & $23 \pm 1$ & $22 \pm 4$ & 96 & $130^{\mathrm{B}}$ & 100 \\
\hline
\end{tabular}

Cardiac function was measured in young adult ABKO and WT mice of both sexes (8-10 weeks old for tail cuff systolic BP and HR, 14 weeks old for echocardiography). Echocardiographic calculations were as in Table 2. Values are mean \pm SEM. $P<0.05,{ }^{A} A B K O$ vs. WT, B ${ }^{B}$ male vs. female WT, C male vs. female ABKO. 


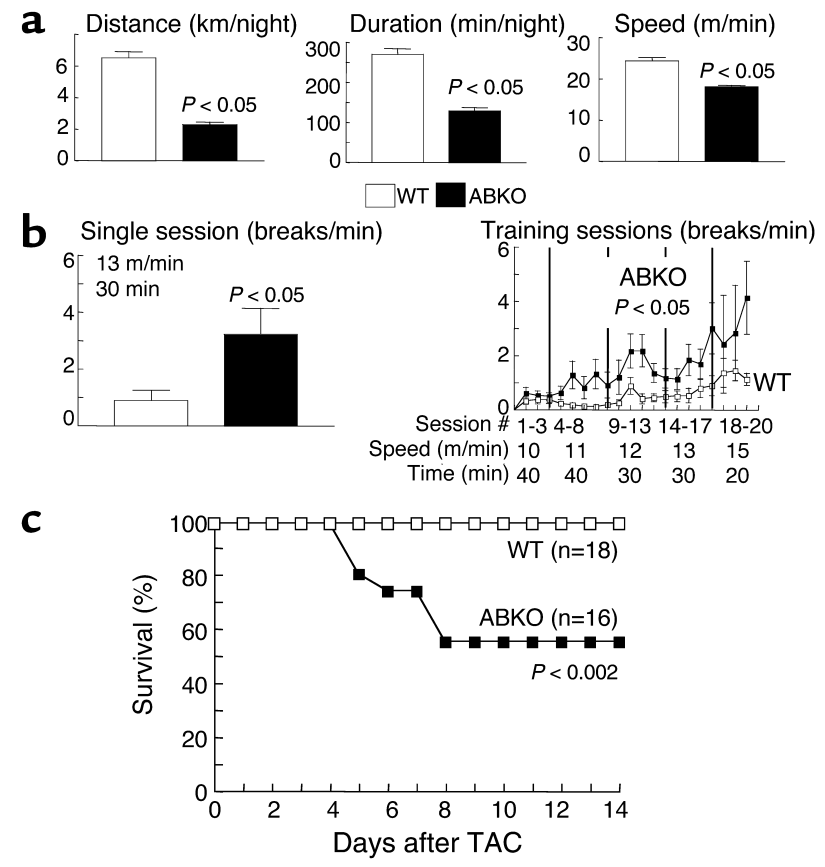

\section{Figure 6}

Response of the ABKO mice to stress. Ten- to twelve-week-old male $A B K O$ and WT mice were used. (a) Exercise: free wheel running. Mice were given access to a running wheel for 12 hours on each of 30 consecutive nights, and distance, duration, and speed were recorded by a chronometer attached to the wheel ( $n=4-5$ mice each group). (b) Exercise: motorized treadmill. Mice were placed on a motorized treadmill set at the speed and for the duration indicated, and the number of times the motivational bar was touched, indicating failure to maintain treadmill speed, was recorded as breaks per minute. The left panel shows a single session ( $n=8-9$ mice per group), and the right panel shows 20 consecutive daily training sessions $(n=9-10)$. (c) TAC was done in congenic mice, and survival was recorded over 14 days.

sus $100 \%$ in the WT mice $(P<0.002$; Figure $6 \mathrm{c})$. ABKO mice died at 5-8 days after TAC (Figure $6 \mathrm{c}$ ), and heart failure was evident in autopsied ABKO mice by fluid in the pleural and peritoneal cavities and thrombi in the atria. In the few ABKO mice that survived to 2 weeks, overall hypertrophy after TAC was the same as observed in WT mice. TAC increased HW/BW by $153 \%$ in ABKO mice, as compared with a $150 \%$ increase in WT mice $(P=\mathrm{NS}$ versus $\mathrm{ABKO})$. Thus, $\alpha_{1}$-ARs were not required for the increase in heart size after pressure overload, but their absence caused death due to heart failure.

\section{Discussion}

Here we characterized a double $\alpha_{1}$-AR KO to show that the $\alpha_{1 \mathrm{~A} / \mathrm{C}}$ and $\alpha_{1 \mathrm{~B}}$ subtypes are together required for normal cardiac hypertrophy during postnatal life. Only the male $\mathrm{ABKO}$ mice had reduced heart growth, but both males and females had normal BP and bradycardia. The mechanism of the small heart was reduced Erk signaling, at least in part. These results indicate a sex-specific and load-independent role for catecholamines and $\alpha_{1}$ ARs in physiological hypertrophy, a role not revealed in earlier single $\mathrm{KOs}(12,13)$.
The ABKO eliminated cardiac $\alpha_{1}$-AR binding and caused a $40 \%$ reduction in growth of the male ABKO heart after weaning. The smaller heart was explained by smaller myocytes, and terminal differentiation was normal. The following supported a direct effect of $\alpha_{1}-\mathrm{AR}$ signaling on myocyte hypertrophy in vivo: myocyte-specific mRNAs and Erk1/2 signaling were reduced, other organs were normal, and $\mathrm{BP}$ and ventricular wall stress were unchanged. A direct effect was shown initially by studies in myocyte culture $(2,5,6)$.

Cardiac adrenergic innervation increases greatly from birth to weaning (1), the $\alpha_{1 \mathrm{~A} / \mathrm{C}}$ subtype is first detected in the mouse heart at weaning (28), and the ABKO cardiac phenotype became evident after weaning. By weaning, myocyte DNA synthesis is largely complete, and subsequent growth of the heart is due to myocyte hypertrophy $(1,21,22)$. Taken together, the findings suggest a model in which increased cardiac sympathetic innervation after weaning, increased norepinephrine release during daily life, and subsequent activation of $\alpha_{1}$-ARs play an important role in the physiological myocyte hypertrophy of normal postnatal development.

The validity of this model would seem to be challenged by the normal growth of the female ABKO heart. However, a body of evidence indicates that sympathetic activation is significantly lower in females than in males (29, $30)$. Lower sympathetic tone in females can explain female protection from hypertension (29) and could readily account for lesser dependence of female heart growth on $\alpha_{1}$-AR stimulation. Indeed, it was notable that an overall effect of the ABKO was to reduce male heart and myocyte size indices to those of the female. It was also notable that myocyte $\alpha_{1}$-AR levels and signaling were the same in WT males and females. Thus, the ABKO can be seen as defining a sympathetic contribution to normal developmental hypertrophy. Ovariectomy did not unmask a small heart in ABKO females, so the sex difference was not determined by female sex hormones.

We did not see any sex differences in other cardiovascular parameters, as both males and females had normal resting BP and bradycardia. These were unexpected findings. As a class, $\alpha_{1}$-ARs are potent vasoconstrictors, and the single $\alpha_{1 \mathrm{~A} / \mathrm{C}} \mathrm{KO}$ is hypotensive (13). On the other hand, the single $\alpha_{1 \mathrm{~B}} \mathrm{KO}$ is normotensive (12), and overexpression of the $\alpha_{1 \mathrm{~B}}$ with its own promoter causes hypotension (9). Thus, the ABKO might combine offsetting effects on BP. Alternately, reduced cardiac output in the ABKO mouse might stimulate a reflex increase in $\mathrm{BP}$ through the vascular $\alpha_{1 \mathrm{D}}$ subtype (31). HR is not altered significantly in the single $\alpha_{1 \mathrm{~A} / \mathrm{C}}$ or $\alpha_{1 \mathrm{~B}} \operatorname{KOs}(12,13)$, and $\alpha_{1}$-AR stimulation does not change HR in the mouse when the baroreflex is blocked (13). The mechanisms of normotension and bradycardia require further study, but the small male ABKO heart was not explained by altered loading.

Insulin/PI3K/Akt and Erk are two pathways so far implicated in physiological hypertrophic signaling (23-26, 32). Reduced Erk signaling was likely one mechanism for reduced hypertrophy in the ABKO mouse, because Erk activity was reduced in the intact $\mathrm{ABKO}$ heart, and $\alpha_{1}$-AR 
stimulation of Erk was lost in isolated ABKO myocytes. However, reduced Erk activity might not explain the entire $\mathrm{ABKO}$ phenotype. $\alpha_{1}$-AR stimulation of Erk is also lost in the single $\alpha_{1 \mathrm{~A} / \mathrm{C}} \mathrm{KO}$ heart (data not shown), but heart size is normal in the single $\alpha_{1 \mathrm{~A} / \mathrm{C}} \mathrm{KO}$ (13). On the other hand, PKC $\varepsilon$ activation is lost in the single $\alpha_{1 \mathrm{~B}} \mathrm{KO}(33)$, and PKC $\varepsilon$ can stimulate a physiological signaling in the mouse heart (34). Thus, the small-heart phenotype might be seen only in the double-subtype KO because the subtypes couple to distinct signaling pathways, which together are essential for developmental hypertrophy.

It was notable in this regard that endothelin and insulin had normal Erk and Akt signaling in ABKO myocytes. These results implied that $\alpha_{1}$-AR effects on postnatal heart growth could not be compensated for by these other hypertrophic agonists, or by the many other Gq-linked systems implicated in hypertrophy. Indeed, it seems likely that $\alpha_{1}$-ARs/Erk and insulin/ PI3K/Akt $(24-26,32)$ represent independent pathways for developmental hypertrophy.

Finally, the male ABKO heart not only was small but also had abnormal function. Contractile function in vivo at rest was intact, with normal ejection fraction and fractional shortening by echocardiography. However, cardiac output was decreased significantly in conscious mice, due to the combination of a smaller heart and a slower HR. With stress, exercise capacity was reduced significantly, most likely by an impaired increase in cardiac output. Furthermore, pressure overload caused death due to heart failure in the ABKO mice that was not observed in WT mice. Thus, $\alpha_{1}$-ARs were required for an adaptive response to cardiac stress. Preliminary data suggest abnormal remodeling in $\mathrm{ABKO}$ mice after $\mathrm{TAC}$, and therefore the $\mathrm{ABKO}$ mouse might help define a physiological contribution to the hypertrophic response that follows a pathological stimulus.

\section{Acknowledgments}

This work was supported by the NIH (P.C. Simpson and E. Foster), the Swiss National Science Foundation (grant 31-51043.97, to S. Cotecchia), the Department of Veteran Affairs (P.C. Simpson), fellowships from the Canadian Heart and Stroke Foundation and the American Heart Association, Western States Affiliate (to D.G. Rokosh) and from the Cardiovascular Research Institute at UCSF (T32HL07731, to T.D. O'Connell).

1. Rakusan, K. 1984. Cardiac growth, maturation and aging. In Growth of the heart in health and disease. R. Zak, editor. Raven Press. New York, New York, USA. 131-164.

2. Simpson, P.C., Kariya, K., Karns, L.R., and Long, C.S. 1990. The $\alpha 1$-adrenergic receptor in left ventricular hypertrophy. Journal of Vascular Medicine and Biology. 2:236-246.

3. Rapacciuolo, A., et al. 2001. Important role of endogenous norepinephrine and epinephrine in the development of in vivo pressure-overload cardiac hypertrophy. J. Am. Coll. Cardiol. 38:876-882.

4. Thomas, S.A., Matsumoto, A.M., and Palmiter, R.D. 1995. Noradrenaline is essential for mouse fetal development. Nature. 374:643-646.

5. Simpson, P. 1983. Norepinephrine-stimulated hypertrophy of cultured rat myocardial cells is an alpha ${ }_{1}$-adrenergic response. J. Clin. Invest. 72:732-738.

6. Simpson, P. 1985. Stimulation of hypertrophy of cultured neonatal rat heart cells through an $\alpha_{1}$-adrenergic receptor and induction of beating through an $\alpha_{1}$ - and $\beta_{1}$-adrenergic receptor interaction: evidence for independent regulation of growth and beating. Circ. Res. 56:884-894.
7. Rokosh, D.G., et al. 1996. $\alpha_{1}$-Adrenergic receptor subtype mRNAs are differentially regulated by $\alpha_{1}$-adrenergic and other hypertrophic stimuli in cardiac myocytes in culture and in vivo: repression of $\alpha_{1 \mathrm{~B}}$ and $\alpha_{1 \mathrm{D}}$ but induction of $\alpha_{1 \mathrm{C} . J}$. Biol. Chem. 271:5839-5843.

8. Milano, C.A., et al. 1994. Myocardial expression of a constitutively active $\alpha 1 \mathrm{~B}$-adrenergic receptor in transgenic mice induces cardiac hypertrophy. Proc. Natl. Acad. Sci. U. S. A. 91:10109-10113.

9. Zuscik, M.J., et al. 2001. Hypotension, autonomic failure, and cardiac hypertrophy in transgenic mice overexpressing the $\alpha 1 \mathrm{~B}$-adrenergic receptor. J. Biol. Chem. 276:13738-13743.

10. Akhter, S.A., et al. 1997. Transgenic mice with cardiac overexpression of $\alpha 1 \mathrm{~B}-$ adrenergic receptors. In vivo $\alpha 1$-adrenergic receptor-mediated regulation of $\beta$-adrenergic signaling. J. Biol. Chem. 272:21253-21259.

11. Lin, F., et al. 2001. Targeted $\alpha_{1 \mathrm{~A}}$-adrenergic receptor overexpression induces enhanced cardiac contractility but not hypertrophy. Circ. Res. 89:343-350.

12. Cavalli, A., et al. 1997. Decreased blood pressure response in mice deficient of the $\alpha_{1 b}$-adrenergic receptor. Proc. Natl. Acad. Sci. U. S. A. 94:11589-11594.

13. Rokosh, D.G., and Simpson, P.C. 2002. Knockout of the $\alpha 1 \mathrm{~A} / \mathrm{C}$-adrenergic receptor subtype: the $\alpha 1 \mathrm{~A} / \mathrm{C}$ is expressed in resistance arteries and is required to maintain arterial blood pressure. Proc. Natl. Acad. Sci. U. S. A. 99:9474-9479.

14. Rohrer, D.K., Chruscinski, A., Schauble, E.H., Bernstein, D., and Kobilka, B.K. 1999. Cardiovascular and metabolic alterations in mice lacking both $\beta 1$ - and $\beta 2$-adrenergic receptors. J. Biol. Chem. 274:16701-16708.

15. Hein, L., Altman, J.D., and Kobilka, B.K. 1999. Two functionally distinct $\alpha 2$-adrenergic receptors regulate sympathetic neurotransmission. Nature. 402:181-184.

16. Deng, X.-F., Rokosh, D.G., and Simpson, P.C. 2000. Autonomous and growth factor-induced hypertrophy in cultured neonatal mouse cardiac myocytes: comparison with rat. Circ. Res. 87:781-788.

17. Stewart, A.F.R., et al. 1994. Cloning of the rat $\alpha_{1 \mathrm{C}}$-adrenergic receptor from cardiac myocytes: $\alpha_{1 \mathrm{C}}, \alpha_{1 \mathrm{~B}}$, and $\alpha_{1 \mathrm{D}}$ mRNAs are present in cardiac myocytes, but not in cardiac fibroblasts. Circ. Res. 75:796-802.

18. Nakamura, A., et al. 2001. LV systolic performance improves with development of hypertrophy after transverse aortic constriction in mice. Am.J. Physiol. Heart Circ. Physiol. 281:H1104-H1112.

19. Zhou, Y.Y., et al. 2000. Culture and adenoviral infection of adult mouse cardiac myocytes: methods for cellular genetic physiology. Am. J. Physiol. Heart Circ. Physiol. 279:H429-H436.

20. Chang, K.C., et al. 1997. Thyroid hormone improves function and $\mathrm{Ca}^{2+}$ handling in pressure overload hypertrophy. Association with increased sarcoplasmic reticulum $\mathrm{Ca}^{2+}$-ATPase and $\alpha$-myosin heavy chain in rat hearts. J. Clin. Invest. 100:1742-1749.

21. Soonpaa, M.H., et al. 1997. Cyclin D1 overexpression promotes cardiomyocyte DNA synthesis and multinucleation in transgenic mice. J. Clin. Invest. 99:2644-2654.

22. Liao, H.S., et al. 2001. Cardiac-specific overexpression of cyclin-dependent kinase 2 increases smaller mononuclear cardiomyocytes. Circ. Res. 88:443-450.

23. Bueno, O.F., and Molkentin, J.D. 2002. Involvement of extracellular signalregulated kinases $1 / 2$ in cardiac hypertrophy and cell death. Circ. Res. 91:776-781.

24. Shioi, T., et al. 2000. The conserved phosphoinositide 3-kinase pathway determines heart size in mice. EMBOJ. 19:2537-2548.

25. Shioi, T., et al. 2002. Akt/protein kinase B promotes organ growth in transgenic mice. Mol. Cell. Biol. 22:2799-2809.

26. Shiojima, I., et al. 2002. Akt signaling mediates postnatal heart growth in response to insulin and nutritional status. J. Biol. Chem. 277:37670-37677.

27. McCloskey, D.T., et al. 2002. $\alpha 1$-Adrenoceptor subtypes mediate negative inotropy in myocardium from $\alpha 1 \mathrm{~A} / \mathrm{C}$-knockout and wild type mice.J. Mol. Cell. Cardiol. 34:1007-1017.

28. O'Connell, T.D., Rokosh, D.G., and Simpson, P.C. 2001. Cloning and characterization of the mouse $\alpha 1 \mathrm{C} / \mathrm{A}$-adrenergic receptor gene and analysis of an $\alpha 1 \mathrm{C}$ promoter in cardiac myocytes: role of an MCAT element that binds transcriptional enhancer factor-1 (TEF-1). Mol. Pharmacol. 59:1225-1234.

29. Hinojosa-Laborde, C., Chapa, I., Lange, D., and Haywood,J.R. 1999. Gender differences in sympathetic nervous system regulation. Clin. Exp. Pharmacol. Physiol. 26:122-126.

30. Evans, J.M., et al. 2001. Gender differences in autonomic cardiovascular regulation: spectral, hormonal, and hemodynamic indexes. J. Appl. Physiol. 91:2611-2618.

31. Tanoue, A., et al. 2002. The $\alpha_{1 \mathrm{D}}$-adrenergic receptor directly regulates arterial blood pressure via vasoconstriction. J. Clin. Invest. 109:765-775. doi:10.1172/JCI200214001.

32. Belke, D.D., et al. 2002. Insulin signaling coordinately regulates cardiac size, metabolism, and contractile protein isoform expression. J. Clin. Invest. 109:629-639. doi:10.1172/JCI200213946.

33. Deng, X.-F., Rokosh, D.G., and Simpson, P.C. 1999. $\alpha 1$-Adrenergic receptor subtypes activate different PKC isoforms in mouse heart. Circulation. 100:I-566. (Abstr.)

34. Mochly-Rosen, D., et al. 2000. Cardiotrophic effects of protein kinase C $\varepsilon$ : analysis by in vivo modulation of PKCe translocation. Circ. Res. 86:1173-1179. 